\title{
Rwanda turning tide on HIV/AIDS
}

$\mathrm{R}$ wanda appears to be stemming the tide of the HIV/AIDS epidemic as health experts report that the HIV prevalence rate in this small East African nation has fallen below 3\% from a staggering $13 \%$ in the 1990s.

The country has "dramatically" reduced the burden of HIV/AIDS by scaling up education and awareness programs, prevention activities and access to treatment, says Dr. Placidie Mugwaneza, head of HIV prevention at TRAC Plus, the nation's centre for infectious disease control.

The first case of HIV in Rwanda was reported in 1983. Just three years later, with a national HIV prevalence of more than $17 \%$ among urban populations, Rwanda was one of the African nations hardest hit by the epidemic (www.usaid.gov/our_work/global_health /aids/Countries/africa/rwanda.pdf).

Much of the country's health infrastructure was gutted during the 1994 genocide (in which an estimated 20\%, or 800000 , of the Tutsi population was massacred by the Hutu regime), and widespread rape caused HIV infection to spread rapidly, particularly in "squalid, violent" refugee camps (www.moh.gov.rw/index.php?option =com_docman\&task=doc_download $\&$ gid=137\&Itemid=14).

Today, the country's adult HIV prevalence rate has dropped to less than $3 \%$, or about half the rate of other East African nations such as Uganda and Kenya, down from $13 \%$ in 2000 , says Dr. Anita Asiimwe, executive secretary of Rwanda's National AIDS Control Commission.

Rates of new HIV infections and AIDS deaths also decreased in the same period, she adds. "Quite a lot has been done to be able to achieve this," not least the "massive sensitization of the population to understand the HIV epidemic, and be able to take preventative measures."

"Most people are now aware there is an HIV/AIDS epidemic in our country, and understand both how they can contract and prevent HIV/AIDS," Asiimwe explains.

The expansion of preventive testing and counselling services has played a "critical role," she says. "Back in 2000, barely any health facilities offered voluntary counselling and testing services,

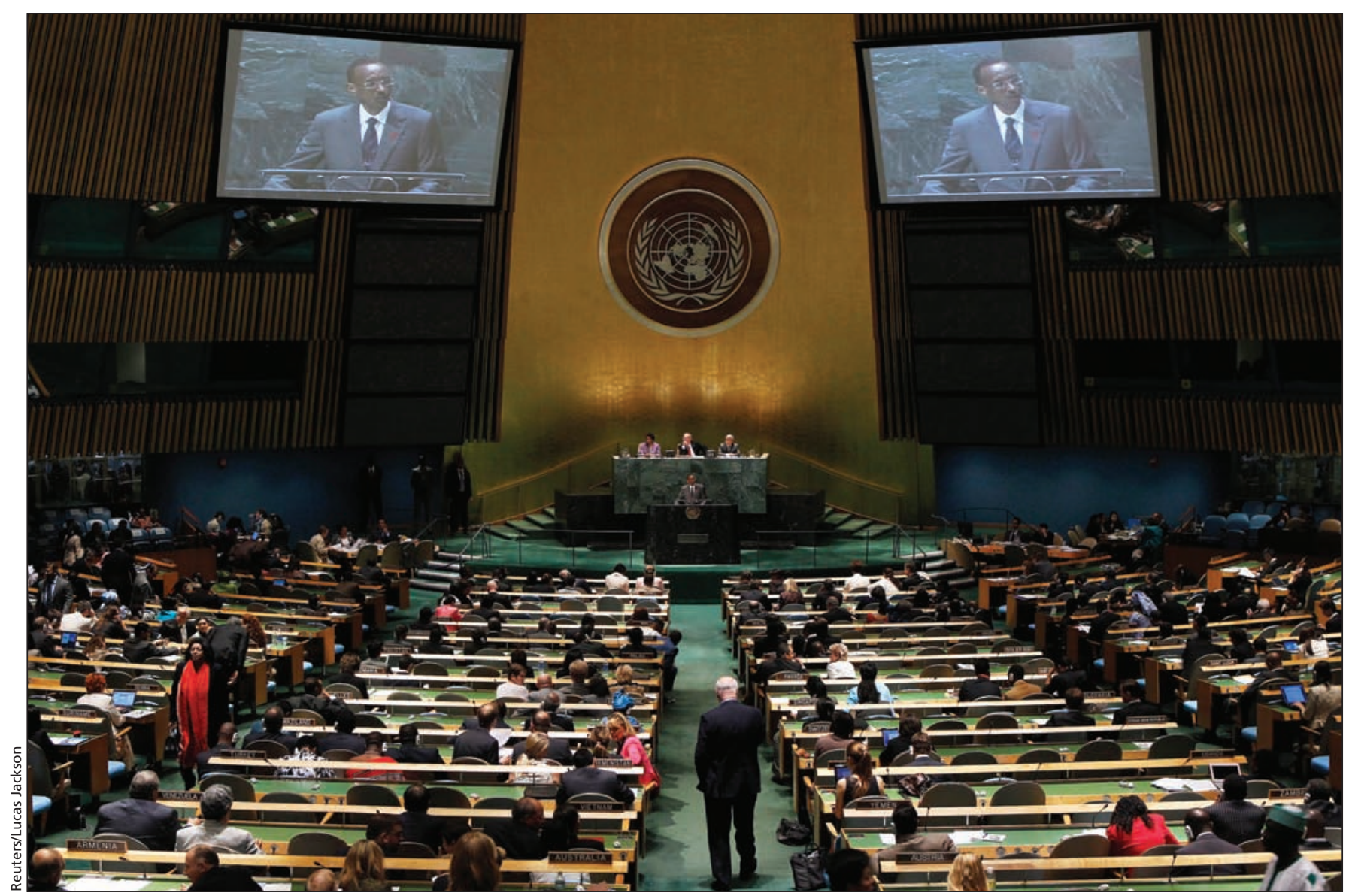

Paul Kagame, president of the Republic of Rwanda, updates the United Nations General Assembly about his country's advances in treating AIDS while speaking at the 2011 High Level Meeting on AIDS at the UN Headquarters in New York City, New York, in June. 
but now more than $85 \%$ of the health facilities across the country offer these services to Rwandans."

Some 417 Rwandan health facilities now provide voluntary counselling and testing services, up from just 15 in 2001 (www.moh.gov.rw/index.php?option= com_docman\&task=doc_download\& gid=223\&Itemid=14). Testing has become far more commonplace among Rwandan couples, rising to $84 \%$ in 2009, from $13 \%$ in 2003.

Services for preventing mother-tochild transmission of HIV have also been scaled up, with the number of facilities offering dedicated mother-tochild-transmission prevention services having mushroomed to 382 in 2010 from 11 in 2001.
Some $98 \%$ of pregnant women who receive antenatal care are now tested for HIV, and $90 \%$ of HIV-infected pregnant women receive antiretroviral drugs to prevent transmission to their newborns, says Mugwaneza. As a result, mother-tochild transmission rates decreased to $2.3 \%$ in 2010 from $30.5 \%$ in 2001 . HIV prevalence among pregnant women dropped to $2.6 \%$ from $9.1 \%$ over the past decade.

Moreover, Rwanda has now achieved one of the highest coverage rates of antiretroviral therapy in Africa, with more than $97 \%$ of those who are eligible for the therapy receiving it. As of 2007, Rwanda boasted 150 antiretroviral therapy centres and, for most patients, treatment is free.
Although more than three-quarters of Rwandans now live within five kilometers of a health facility, gaps in coverage remain, Asiimwe says. "There are still, for example, Rwandans who have to travel quite a distance to get to the facilities that offer these services."

Many Rwandans, particularly in urban areas, also continue to engage in risky behaviours, she adds. To achieve an "HIV-free generation," Rwandans must "take full responsibility for their sexual health and not leave the fight against HIV/AIDS to national programs and institutions." - Lauren Vogel, CMAJ

CMAJ 2011. DOI:10.1503/cmaj.109-3938 